\title{
O Quadro de classificação periódica da sustentabilidade
}

\author{
Uma metáfora para a química verde e ecologia industrial
}

\section{Resumo:}

Apresenta-se uma metáfora gráfica sobre o Quadro de Classificação Periódica (QCP) que consiste em adicionarIhe três ingredientes a ter em conta quando se pratica presentemente a Química Industrial tendo em vista o Desenvolvimento Sustentável: a Energia, a Economia e o Ambiente - estes "elementos" metafóricos pervagam a química do mundo real, sendo a sua consideração sempre fundamental para a implementação da Sustentabilidade (são "super-elementos"). Por isso, a sua inclusão no metafórico QCP da Sustentabilidade permite que os químicos os tenham sempre presentes, a par dos elementos materiais, para atender às suas consequências quando realizam reacções químicas à escala industrial.

Science is necessary, but not sufficient, in establishing one's view of the world. Schroedinger, British Journal for the Philosophy of Science, 3 (1952) 109

A metáfora (análise e compreensão de uma situação a partir das suas semeIhanças com outra mais bem conhecida) é muito importante para o desenvolvimento das ideias científicas sobre factos e conceitos novos, sendo usada, por exemplo, para ilustrar como os modelos se comportam com respeito às teorias científicas [1]. Recentemente, o químico inorgânico T. L. Brown discutiu a utilização da metáfora numa diversidade de campos da Química e Bioquímica, demonstrando a sua importância nos avanços de conhecimento em domínios tão diversos como a estrutura atómica, a bioquímica celular, a dobragem de proteínas, o aquecimento global, etc. [2]. No ensino da química, as metáforas são muito eficazes e utilizadas para apresentar matérias abstractas e pouco familiares com base no conhecimento e experiência anterior dos alunos sobre outras matérias já dominadas e o próprio mundo real [3-9]. Para este fim, têm-se usado quer metáforas linguísticas [3,6,7], quer metáforas gráficas [8], quer metáforas conceptuais [2,4,9], estas últimas muito adequadas na formulação de modelos para a interpretação do comportamento dos sistemas microscópicos (átomos e moléculas) [2,4]. Na abordagem dos sistemas complexos que constituem o mundo real, a metáfora é também muito útil para a construção de modelos simplificados, tendo por isso larga aplicação, por exemplo, quer em ciências ambientais, quer na Ecologia Industrial para implementação da Química Verde [10]. O próprio conceito de Ecologia Industrial tem por fundamento uma metáfora com base na ecologia biológica [11,12] e usa outras metáforas, por exemplo, a de metabolismo industrial [13].

Este artigo tem como objectivo a apresentação de uma metáfora construída a partir do Quadro de Classificação Periódica (QCP) que conduz à expansão do mesmo com elementos adicionais, metafóricos, para vincar a importância da consideração da energia, da economia e do ambiente na procura do Desenvolvimento Sustentável ou Sustentabilidade. A ideia base da metáfora é que, numa altura em que a Química deve ser praticada tendo em vista uma mudança da trajectória de avanço da Civilização Industrial para esta entrar na rota da Sustentabilidade, se impõe o uso de um novo QCP metafórico que, além dos elementos materiais, inclua os ingredientes adicionais que os químicos têm de integrar rotineiramente na sua actividade para contribuir para aquela mudança - para isso se introduz o QCP da Sustentabilidade. Esta metáfora gráfica tem vindo a ser usada com êxito como introdução a uma série de aulas sobre Química Verde e Ecologia Industrial integradas na cadeira de Química Industrial da Licenciatura em Química deste Departamento (Faculdade de Ciências da Universidade do Porto).

\section{Os novos "elementos" - os super-elementos}

Os elementos químicos, que constituem o QCP, são as unidades básicas que os químicos académicos que trabalham no laboratório (e que praticam a Química Académica ou Química Laboratorial) usam para construir novas moléculas - isto é, para preparar novos compostos, 
que normalmente sintetizam, em pequena escala, a partir de outros compostos (e não directamente a partir apenas de elementos isolados). Os elementos químicos são também os constituintes básicos do mundo material que constitui o ambiente - a sua existência e modos de ocorrência neste são objecto de estudo em Química Ambiental. Por outro lado, o modo como os elementos e os compostos que os integram são manipulados em larga escala pela Química Industrial, que fabrica os produtos químicos, e por outras actividades que usam estes produtos para os mais variados fins, tem como consequência a dispersão e deposição no ambiente de substâncias diversas, nem sempre inócuas - poluentes e resíduos. Também estes problemas são objecto de estudo pela Química Ambiental.

Os químicos industriais, quando fabricam compostos em larga escala, na Indústria Química, que realiza a Química Industrial, usam, além dos elementos químicos e em paralelo com estes, outros ingredientes não materiais. Para evidenciar a sua importância, esses ingredientes podem ser metaforicamente designados como "elementos". O papel destes outros "elementos" na Química Industrial é tão ou mais importante que a dos elementos materiais; e como tais "elementos" intervêm conjuntamente com estes e supletivamente a eles, podem ser adequadamente designados por super-elementos ou pan-elementos. Embora sejam quase sempre ignorados ou subalternizados na Química Laboratorial, os super-elementos, dada a sua importância e omnipresença no mundo real, condicionam completamente, ou quase, a implementação da Química Industrial - determinam os compostos que se fabricam/não fabricam com os elementos materiais do QCP, a via porque se fabricam, quando se fabricam, etc. Além disso, o modo como os super-elementos são manipulados (em conjunto!) tem enorme importância sobre os efeitos na ecosfera da Química Industrial e de muitas das outras actividades, praticadas pelas modernas sociedades industrializadas emergentes da Revolução Industrial, que utilizam produtos químicos. Por isso, os super-elementos têm uma importância alargada, que transcende a Química, seja Académica seja Industrial - têm um alcance societário muito amplo. Este facto justifica que, tal como os elementos materiais, devam ser incluídos no QCP, para que os químicos possam recordá-los sempre e mentalizar-se para dirigir sempre as suas actividades à perseguição da Sustentabilidade

Os super-elementos são três (ver a Fig. 1) e vão ser considerados a seguir por ordem crescente da sua importância para a implementação da Sustentabilidade.

Energia. O primeiro super-elemento tem um nome universalmente aceite (Energia), mas é vulgarmente representado por vários símbolos diferentes $(E, \tau$, W, etc.). É conhecido desde há muito tempo, pois o seu domínio desempenhou sempre um papel importante no desenvolvimento da Civilização - foi uma das mais importantes forças mo- trizes desta. Na realidade, emergiu logo no Paleolítico, com a actividade braçal do homem para recolha de alimentos a partir das plantas e na caça - energia muscular ou metabólica; e com o uso intermitente do fogo, mantido continuamente a partir de incêndios naturais só até que a fogueira inadvertidamente se apagava - energia térmica ou calor. Nos princípios do Neolítico, a invenção humana de fazer fogo, quando era desejado, por fricção de dois pequenos paus de madeira dura (cerca de 7000 anos a. C., em África) marca o início do domínio da energia pelo Homem. Aliás, a Revolução Neolítica, a transição da vida nómada para a vida sedentária suportada na agricultura e pecuária, consistiu, em termos de energia, num primeiro grande passo em frente da Civilização - o domínio (possível!) da fixação de energia solar pela fotossíntese das plantas cultivadas, transformando-a na energia química dos cereais e outros produtos agrícolas, a energia ingerida na alimen-

\section{OS SUPER-ELEMENTOS DA SUSTENTABILIDADE}

“ELEMENTO" 1

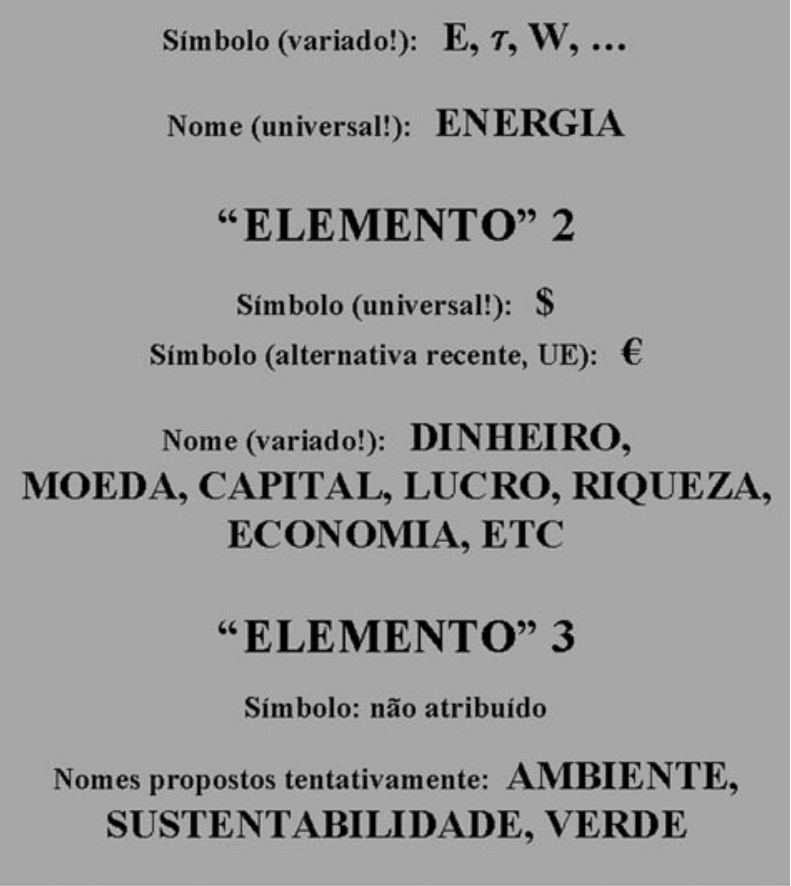


tação que acciona o corpo humano. No entanto, com o Neolítico surgiu também, inadvertidamente, uma invenção inconveniente, sempre maldita depois - o trabalho: o trabalho no campo, que cansava, porque exigia energia muscular em regime continuado. Por isso, o Homem reagiu, inventando o arado manual (cerca de 3.500 anos a. C.), que exigia menos esforço que a sachola; e, depois, domesticando animais de tiro (bois, etc.) e pondo-os a puxar o arado inventou o domínio da energia muscular animal. O domínio da energia muscular foi também responsável por um deslize civilizacional - a escravatura, para obter trabalho a partir da possessão de semeIhantes. Numa altura em que a posse de bens era limitada, o principal espólio que podia ser saqueado na guerra não era bens materiais, mas sim inimigos aprisionados vivos, para os escravizar e Ihes explorar o trabalho braçal - o acicate do domínio da energia a funcionar, pela primeira vez, para fazer o Mal (!), que depois se repetiria em variadas situações (exemplo supremo do século XX: o domínio da energia nuclear para obter a bomba atómica).

Depois, ao longo da História, foi-se aprendendo a dominar formas de energia natural abiótica, por exemplo, utilizar a energia cinética da água dos rios (moinhos de água, inventados na Grécia, no século I a.C.) e do vento (moinhos de vento, com origem na Pérsia, século VII) para moer cereais (substituindo o trabaIho braçal!). Estes maquinismos foram sendo aperfeiçoados e acabaram por permitir a conversão destas formas de energia em energia mecânica: a hídrica (cinética e potencial), para utilização em oficinas semiartesanais (no século XVIII, por exemplo, em serrações, para accionar serras; nas oficinas de ferreiros, para movimentar os martelos para a forja do ferro, etc.) e nas primeiras fábricas de fiação e tecelagem mecânica, nos primórdios da Revolução Industrial; a eólica, para tirar água de poços ou drenar zonas inundadas (na Holanda, a partir do século XIV). Toda estes processos envolviam a produção de energia mecânica a partir de formas de energia renovável - ou, na linguagem actual da
Sustentabilidade, energia verde (com a óbvia excepção da escravatura!).

Nos fins do século XVII, a invenção da máquina a vapor, que impulsionou a Revolução Industrial, um segundo grande passo no desenvolvimento da Civilização, envolveu também o domínio da energia - mais precisamente, da transformação da energia química do carvão em energia mecânica em grandes quantidades, que permitiu o uso intensivo desta em variadas actividades: produção industrial, extracção do próprio carvão (retroacção positiva no sistema de produção de energia!) e de minérios do subsolo, transportes (caminho de ferro, barcos a vapor), etc. Depois, na segunda metade do século XIX, as invenções dos motores de explosão (por Otto) e de combustão interna (por Diesel) permitiram o domínio da obtenção de energia mecânica em maquinismos auto-transportáveis, a partir de derivados de um segundo combustível fóssil, o petróleo - e trouxeram depois o transporte pessoal por automóvel (e não só), cujo uso cresceu intensamente ao longo do século XX, com consequências nefastas hoje bem conhecidas (o arado e o automóvel foram as grandes invenções que mudaram o aspecto da superfície da Terra - provocaram ambos alterações brutais na paisagem ambiental!). 0 desenvolvimento do automóvel implicou que o petróleo passasse a ser a fonte de energia mais utilizada. Por outro lado, a partir dos fins do século XIX começou-se a produzir energia eléctrica em larga escala - e o século XX testemunhou uma expansão enorme da sua distribuição doméstica, a serviços, à indústria, etc., que mudou muito os hábitos e a comodidade de vida. A electricidade é maioritariamente obtida por combustão de carvão, fuelóleo ou, mais recentemente, gás natural, através da produção de vapor de água sobreaquecido a alta pressão e transformação da respectiva energia de expansão em electricidade por meio de turbinas e geradores eléctricos (são também usados outros processos de produção, por exemplo, a partir da energia potencial hídrica, em barragens, da energia atómica, etc., mas com menor expressão). Enfim, o século $\mathrm{XX}$ testemunhou o desenvolvimento da "civilização do carbono" - baseada na utilização de quantidades crescentes de energia produzida a partir dos combustíveis fósseis (carvão, petróleo e gás natural, todos constituídos predominantemente por carbono).

Em suma, como a energia se tornou tão fácil de obter com o avanço técnico conseguido na esteira da Revolução Industrial e tão omnipresente na nossa vida diária, além de estar tão entrosada com o desenvolvimento da civilização, acabou por atingir-se uma situação em que se the deixou de dar grande importância - em meados do século XX, a sociedade afluente usava-a mas quase a ignorava! Em 1973, porém, retomou-se plena consciência da sua importância generalizada, quando ocorreu a chamada primeira crise do petróleo. Esta foi provocada por uma subida do preço do petróleo bruto de $70 \%$, em Outubro daquele ano, imposta pela organização de produtores (OPEC, Organization of the Petroleum Exporting Countries), dominada pelos países árabes do Médio Oriente, para defesa dos seus interesses económicos; a que se seguiu, em Dezembro, outro aumento de $130 \%$, provocado por mais uma guerra israelo-árabe (em que Israel foi atacado pelo Egipto e Síria), acompanhado por diminuição da produção e embargo da exportação para os EUA e a Holanda, que tinham suportado Israel naquela guerra. A escassez de petróleo provocou uma crise económica muito forte nos países desenvolvidos do Ocidente - contracção da economia, inflação elevada, etc. Esta crise provocou a reemersão da importância do petróleo, ou mais globalmente, da energia - que se passou a olhar de modo diferente: teve-se de investigar e implementar a poupança de energia na indústria, nos transportes, etc.; por exemplo, na Indústria Química, uma forte consumidora, passou-se a dar maior importância à recuperação de energia libertada nas reacções exotérmicas ou latente nos fluxos de materiais aquecidos, etc. Por outro lado, intensificou-se a prospecção de petróleo em países fora do Médio Oriente (por exemplo, México, Noruega, Reino Unido - Mar do Norte) e desenvolveram-se processos alternativos de produção de energia (gás natural, 
energia nuclear, etc.). Estes esforços conduziram à normalização da situação económica - e, mais importante do que isso, a uma redução no consumo de energia por unidade de bens produzidos. O ano de 1973 já foi chamado o "último ano da energia barata" (na década de setenta o preço do petróleo aumentou dez vezes, embora depois tivesse diminuído) - daí para a frente, a energia passou a ser considerada um ingrediente escasso, que era preciso poupar e recuperar sempre que surgisse oportunidade. Para esta postura contribuiu também um célebre relatório do Clube de Roma (The Limits of Growth, de Meadows e Meadows) [14], publicado na mesma altura (em 1972), em que se chamava a atenção para o facto de a velocidade crescente a que se estavam a despender os recursos naturais não renováveis extraídos do subsolo, incluindo os combustíveis fósseis, passar a ser insustentável dentro de algumas décadas.

Em suma, a "redescoberta" da energia nos anos setenta do século passado trouxe consigo uma importância deste ingrediente que tem sempre de ser considerada em qualquer actividade humana, nomeadamente na indústria e, em particular, na Indústria Química: globalmente, esta é muito ávida de energia - e os químicos industriais devem recordar sempre a necessidade de o seu uso ser parcimonioso.

Dinheiro, Moeda, Economia, etc. O segundo super-elemento tem um símbolo universalmente aceite (\$), embora recentemente tenha surgido outro símbolo alternativo, que ganhou desde logo grande aceitação (€); e é conhecido por vários nomes, formais ou não: Dinheiro, Moeda, Capital, "Massa", Lucro, Riqueza, Economia, etc., preferindo-se aqui este último, mais formal e de alcance mais lato.

Em contraste com o primeiro, este super-elemento não só foi descoberto como também é utilizado há muito tempo, muito antes da Química Industrial, da
Química e da própria Alquimia se terem desenvolvido - o seu uso data do Neolítico, quando o Homem começou a usar cabeças de gado como unidade padrão em trocas de bens e emergiu o conceito de Dinheiro como valor de troca (a palavra pecuniário, usada actualmente com referência ao dinheiro, deriva da palavra latina pecus, que significa gado!). Muito mais tarde, já na História (cerca de 2.000 anos a. C.), evolui-se para algo mais prático - como andar com cabeças de gado atrás quando se ia às compras era incómodo, passou-se a usar pedaços de metais como dinheiro (prata, ferro, etc.), medidos a peso ou por tamanho. No milénio seguinte (cerca de 700 anos a. C., no reino da Lídia, na Anatólia, hoje Turquia), para obstar ao incómodo de pesar ou medir o tamanho das peças de metal durante as transacções comerciais, passou-se a pôr uma marca nelas para definir e certificar o respectivo valor - surgiu a versão original da Moeda. Esta era constituída por lingotes de electro, uma liga de prata e ouro, com forma de feijão mas de grande tamanho, com uma marca obtida por punção com uma matriz mais dura. O uso da moeda permitia realizar os pagamentos por contagem, mais fácil e expedita que a pesagem ${ }^{1}$, e, sobretudo, permitia separar a compra da venda (eliminar a troca!), o que incentivou muito o comércio - não foi por acaso que Creso, o último Rei da Lídia, era dono de uma fortuna imensa, que a História registou como proverbial (o que não impediu que o seu reino fosse conquistado pelos persas, em 546 a. C.). Depois, na Grécia e em Roma, as moedas diminuíram de tamanho e adquiriram a forma de disco usada presentemente, que permitia incluir como marca a esfinge do imperador, rei, etc., que as lançava, importante para vincar o monopólio do lançamento da moeda e para a segurança da certificação (além de estimular a vaidade do mandante). Além de um meio para as trocas de bens, o dinheiro serve para exprimir preços e valores e é a medida principal da riqueza - foi uma invenção polivalente!

A motivação de "ganhar dinheiro", o lucro, para acumular riqueza, foi o agente motriz da quase totalidade da actividade humana desde que foi inventado o comércio e, depois, da actividade industrial em geral - e, também, obviamente, da Química Industrial. Com o avanço da Civilização, os modos de fazer crescer riqueza foram adquirindo maior complexidade e, a partir do século XVIII, desenvolveu-se uma ciência própria para os estudar, teorizar e, sobretudo, aplicar com eficácia, a Economia - a análise e descrição da produção, distribuição e consumo da riqueza, quer a nível pessoal, da empresa, etc. (microeconomia), quer a nível de agregados, nações, etc. (macroeconomia).

Em suma, são desnecessárias mais justificações para se poder afirmar que o "elemento" Economia é sempre muito importante em quase todos os empreendimentos humanos - e que não pode ser ignorado pelos químicos industriais na sua actividade, particularmente quanto à sua componente microeconómica.

Ambiente. O terceiro super-elemento teve génese mais recente: embora conhecido desde que o Homem começou a atentar no meio que o rodeava, e tivesse sido elaborado ao longo do desenvolvimento da Civilização, só emergiu com vigor na década de setenta do século XX, na esteira da publicação do livro "Silent Spring", em 1962, de Rachel Carlson (1907-64), sobre os efeitos destrutivos dos pesticidas na vida dos animais selvagens [15]. Este super-elemento não tem ainda um nome bem definido, muito menos um símbolo: é um elemento muito complexo, ainda não completamente caracterizado, cuja utilização é, na prática, muito complicada e se encontra em investigação (e é de prever que assim continue durante muito tempo). Este super-elemento pode designar-se tentativamente "elemento" Ambiente (possíveis alternativas seriam "elemento" Sustentabilidade ou 
"elemento" Verde), por ter embutido nele a necessidade de preservação do meio ambiente, da saúde humana e das outras espécies biológicas, e dos sistemas ecológicos que nos fornecem recursos naturais e serviços diversos, etc. - o nome Ambiente tem neste contexto um significado lato.

Este "elemento" tem a ver com o facto de a Civilização Industrial em geral, e a Química Industrial em particular, tal como foi implementada ao longo do século XX, ter proporcionado simultaneamente dois efeitos opostos. Por um lado, a sociedade industrializada proporcionou um contributo muito importante para o progresso da Civilização em muitos países (não em todos!) - prosperidade, crescimento económico, melhor qualidade e aumento da esperança de vida, etc. Por outro, a sociedade industrializada, caracterizada pela produção massificada, consumo massificado e produção massificada de resíduos, tem sido responsável pela destruição a ritmo desenfreado de recursos naturais [14] - quer os não renováveis, e por isso susceptíveis ao esgotamento, por exemplo os combustíveis fósseis e certos metais, quer os renováveis, consumidos a velocidade elevada e incompatível com a sua reposição, por exemplo, a madeira das florestas; e acabou por provocar fortes danos no ambiente - por exemplo, poluição dos mais diversos tipos, contaminação de espécies vivas, etc. Para conservar o ambiente e manter o progresso a longo prazo, é necessário passar a implementar a Civilização Industrial de outra maneira, baseando-a em conceitos novos - nomeadamente Desenvolvimento Sustentável (ou Sustentabilidade), Engenharia da Sustentabilidade, Ecologia Industrial, Química Verde, etc.

Em particular, é necessário realizar a Química Industrial de um modo diferente do vigente - introduzindo-lhe uma preocupação constante de minimizar a produção de poluentes e de resíduos, especialmente os tóxicos, aproveitar ao máximo os recursos naturais (materiais e energéticos), preparar preferencialmente compostos inócuos para a saúde humana e ecológica, etc. Este novo processo de implementar a Química Indus- trial, embora ainda numa fase inicial de desenvolvimento, já tem um nome consagrado: é a Química Verde. Esta nova atitude de abordagem da Química, implícita no Desenvolvimento Sustentável e na Engenharia da Sustentabilidade, tem vindo a ganhar aceitação, está em pleno crescimento, e acabará por adquirir uma importância predominante na Química Industrial (e em muitas outras actividades industriais, e não só, em que são usados produtos químicos).

A investigação continuada das características do super-elemento Ambiente, ainda incompleta, conduziu ao aparecimento de uma série de novos conceitos, a partir dos anos setenta do século XX, com o fito de melhorar a integração da actividade humana no meio ambiente, de modo a deteriorá-lo menos. A partir da emergência do Desenvolvimento Sustentável, a natureza fundamental deste "elemento" ficou melhor definida, pelo menos em princípio, quanto ao seu objectivo: procurar atingir a Sustentabilidade, na medida do possível (na prática, porém, a definição do "elemento" Ambiente continua a ser complexa) - outra ideia fundamental que os químicos devem interiorizar.

\section{A posição dos novos "elementos" no QCP}

Caracterizados os novos "elementos", há que discutir como se pode introduzi-los no actual QCP, para obter o QCP do Desenvolvimento Sustentável. Um primeiro ponto que vale a pena referir é que esta inclusão é compatível com a prática histórica de adicionar novos elementos no quadro, à medida que foram descobertos.

\section{Inclusão de novos elementos no QCP}

Esta prática data da própria formulação do QCP por Mendeliev (1834-1907), que à nascença foi uma versão futurista que considerou desde logo elementos ainda não descobertos [16]. Quando Mendeliev gizou O QCP (1869-71), deixou "casas" vagas para inserir três elementos então desconhecidos, cujas propriedades previu: designou-os por eka-boro, eka-alumínio e eka-silício, por ficarem colocados por baixo dos elementos incluídos nestes nomes, numa segunda versão do QCP (1870), dita de "forma curta", em que os grupos foram colocados verticalmente (como na versão actual) - na primeira versão (1869) tinham sido colocados horizontalmente. A previsão funcionou como um acicate para a procura de tais elementos - a sua posterior descoberta (Escândio, em 1879, Gálio, em 1875, descoberto aparentemente sem conhecimento do QCP, e Germânio, em 1886, respectivamente) confirmou as previsões quer quanto à existência dos elementos, quer quanto às suas propriedades. 0 cumprimento das previsões validou as ideias de Mendeliev sobre o comportamento periódico dos elementos e contribui muito para impor definitivamente o QCP (a hipótese de periodicidade das propriedades dos elementos, confirmada como "lei periódica", passou a integrar o corpo de conhecimento científico estabelecido).

Por outro lado, nos fins do século XX, quando foram descobertos, foram adicionados ao QCP os gases raros, de cuja existência até então não se suspeitava, numa coluna ad-hoc no fim dele (só mais tarde, quando se encontrou uma racionalização da forma do QCP, por via da quantificação da estrutura atómica, é que se comprovou que esta escolha de posição tinha sido adequada). Finalmente, nas últimas décadas, têm vindo a ser incluídos no QCP novos elementos artificiais (transuranianos), à medida que o seu fabrico por reacções nucleares é comprovado. Os mais recentes foram o Darmstádtio (Ds, número atómico 110) [17] e o Roentgénio, (Rg, 111) [18,19]. Em suma, a história do QCP mostra que é perfeitamente lícito adicionar-Ihe novos elementos.

Inclusão dos super-elementos no QCP.

Dada a sua importância e omnipresença em Química Industrial e não só, os super-elementos devem ser incluídos no QCP para que os químicos nunca os esqueçam - e, considerando a sua natureza imaterial e as relações íntimas entre eles, os três super-elementos devem constituir uma classe de elementos à parte, distinta dos grupos ou dos períodos dos elementos materiais.

Surpreendentemente, a inclusão no QCP é possível e natural: este tem, nos pri- 
meiros três períodos, muito espaço desperdiçado, não ocupado por elementos. Tal como Mendeliev, quando construiu o seu QCP, deixou "casas" vagas para serem ocupadas por novos elementos a descobrir, poderia dizer-se que o espaço disponível no QCP actual estava reservado para acomodar os três super-elementos. O facto de o espaço ser generoso não levanta problemas, pelo contrário: como estes "elementos" são tão importantes que intervêm sempre em toda e qualquer reacção da Química Industrial, cada um deles merece bem um espaço aumentado, constituído por várias casas justapostas do QCP - tiras dispostas transversalmente neste (ver a Fig. 2). Os locais disponíveis no QCP podem ser designados por "0", "00" e "000", por ordem crescente de importância, sendo então necessário "encaixar" neles os "elementos" Energia, Economia e Ambiente.

O "elemento" Energia, quando considerado isoladamente, é, sem dúvida, o menos importante dos três: trata-se de um ingrediente com natureza semelhante à dos elementos materiais (a equação de Einstein, $E=m c^{2}$, é prova disso), embora mereça mais do que uma "casa" do QCP, para evidenciar que acompanha sempre todos estes, nomeadamente na realização das reacções químicas - deve-se atribuir-lhe, portanto, a posição "O". Na realidade, a grande importância deste "elemento" provém da sua utilização alargada, mas é de natureza societária - resulta da sua interrelação com os outros dois super-elementos.

A distribuição dos "elementos" Economia e Ambiente pelos outros dois locais é mais controversa (ver a Fig. 3). Sem dúvida que estes dois super-elementos têm uma importância superior, que transcende a do elemento Energia, mas tem de se questionar qual deles deve ocupar a posição intermédia ("00") e qual deve ficar na suprema ("000"). $\mathrm{Na}$ situação actual, em que a Economia domina o mundo e imperam as decisões políticas que a suportam, em detrimento da preocupação com o Ambiente, o posicionamento é nitidamente o da parte superior da Fig. 3: o "elemento" Ambiente ocupará o local "OO" e o "elemento" Economia o "000" (fica no topo, pois é

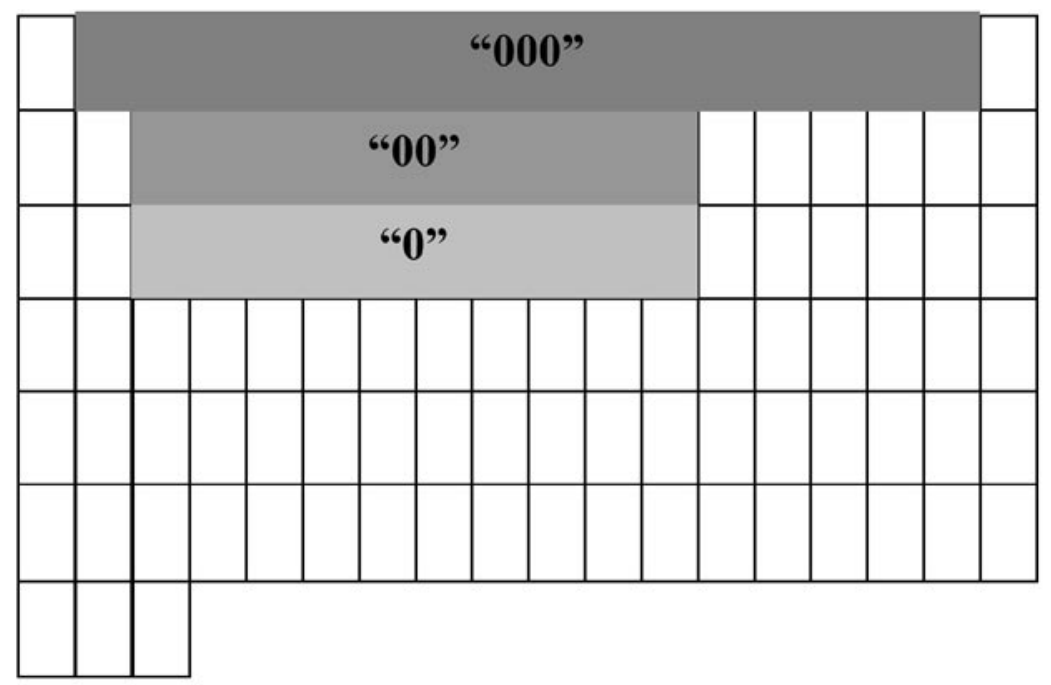

Figura 2 Os "buracos" disponíveis nos três primeiros períodos do QCP constituem óptimos locais (“0", "00" e "000") para encaixar três super-elementos e obter o QCP da Sustentabilidade: o "elemento" que governa quase tudo!). Recorde-se, por exemplo, as reticências quanto à aceitação pelos EUA do acordo de Quioto sobre a limitação da produção de dióxido de carbono e outros gases de estufa - que se deve, fundamentalmente, às repercussões negativas que ela teria na economia americana.
Sustentabilidade: permuta de posições entre os super-elementos Economia e Ambiente. A colocação anterior dos "elementos" Economia e Ambiente, porém, não permite caminhar para a Sustentabilidade - a perseguição desta implica uma troca de posições dos dois super-elementos: no futuro, idealmen-
Figura 3 A versão actual do QCP da Sustentabilidade (em cima) e a sua desejável versão futura (em baixo).

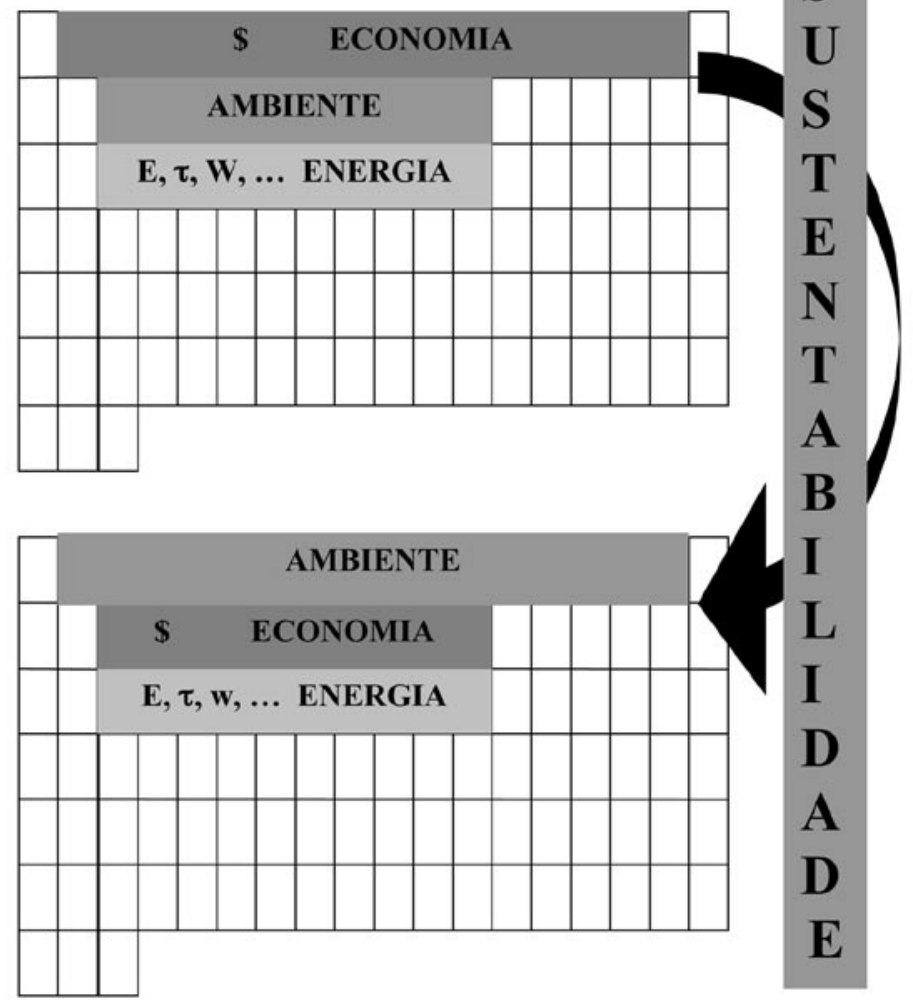


te, o "elemento" Ambiente terá de subir para o local supremo "000" (parte de baixo da Fig. 3), caso contrário não se conseguirá manter o planeta Terra em condições de suportar os humanos em sucessivas gerações. Para operar a mudança de posição (leia-se: para conseguir o Desenvolvimento Sustentável), a sociedade terá de aprender a manejar conjuntamente os "elementos" Economia e Ambiente de modo a trocar as suas posições no QCP. Para isso, o crescimento económico terá de ser feito com uma profunda e permanente preocupação com o ambiente, de modo a remediar os efeitos nocivos que o desenvolvimento dominado apenas pelo super-elemento Economia provocou ao longo do século XX e a promover a plena conservação da ecosfera.

Dada a situação e mentalidade vigente, o processo de mudança de posições será lento e difícil, até porque pode exigir uma certa contracção nas comodidades que os cidadãos dos países avançados actualmente usufruem. No entanto, a Química Verde e a Ecologia Industrial podem potenciar algumas das alterações necessárias, porque permitem satisfazer os requisitos económicos sem deteriorar simultaneamente o ambiente - por isso, têm garantido um papel importante nas mudanças a concretizar.

Justificação histórica da permuta. Para justificar a permuta, pode-se concluir como se começou esta secção, recordando que também Mendeliev teve de trocar posições de pares de elementos para os colocar no QCP em posições definitivas - as chamadas "inversões" (nomeadamente Níquel/Cobalto e lodo/ Telúrio - mais tarde, foram identificadas outras duas). As inversões decorriam de ele utilizar a massa atómica como variável característica definidora dos elementos e não o número atómico, hoje usado como número de ordem dos elementos no QCP (o número atómico só emergiu como grandeza definidora dos elementos após se ter descoberto as partículas subatómicas e formulado a estrutura quântica do átomo - é o número de protões no núcleo atómico). Afinal, também a troca de lugares entre os "elementos"

Figura 4 Mensagens da metáfora do QCP da Sustentabilidade

\section{MENSAGENS DA METÁFORA DO QUADRO DE CLASSIFICAÇ̃̃O PERIÓDICA DA SUSTENTABILIDADE}

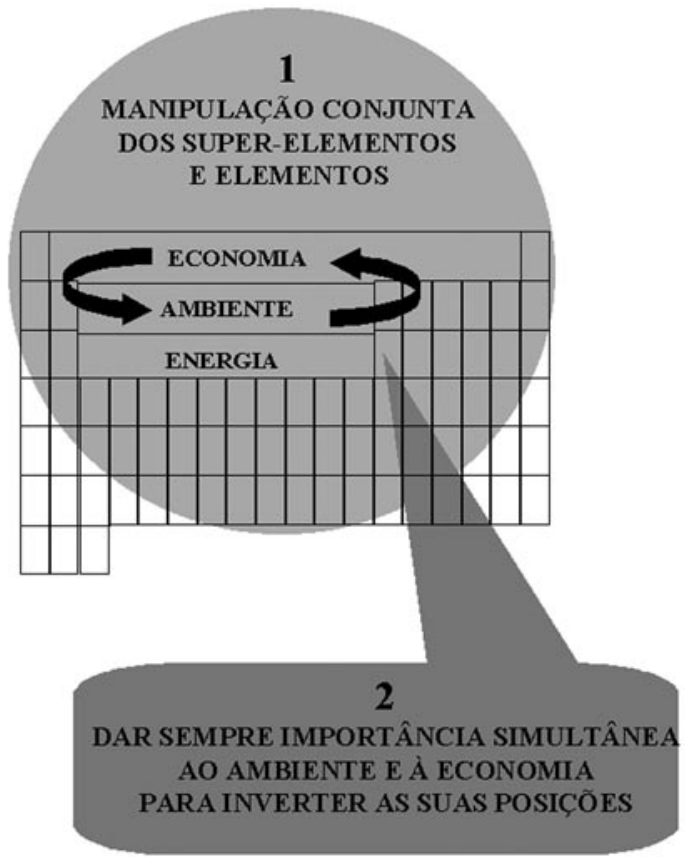

Economia e Ambiente tem precedentes no QCP real, o que mostra a sua exequibilidade.

\section{Conclusão: mensagens da metáfora do} QCP da Sustentabilidade

A metáfora do QCP da Sustentabilidade permite transmitir eficazmente aos químicos e demais utilizadores de substâncias químicas duas mensagens globais (ver a Fig. 4): primeira, devem mentalizar-se para, ao manipular os compostos nas reacções químicas, ter sempre em atenção não só os elementos materiais que os constituem, como também os super-elementos - atender sempre aos aspectos energético e económico e às consequências ambientais das reacções que executam; segunda, no âmbito desta atitude holística, devem dar sempre tanta importância aos aspectos ambientais como aos económicos e perseguir a inversão da valorização relativa deles (para ir realizando, paulatina mas voluntariosamente, a troca de posições dos super-elementos Ambiente e Economia no QCP).

É claro que a troca de posições (leia-se, a perseguição da Sustentabilidade) é de implementação difícil e não pode ser feita instantaneamente - é uma tarefa formidável. Mas também a formulação do QCP por Mendeliev o foi: por um lado, foi um exercício de pensamento holístico, ao contrário da corrente dominante na altura, o pensamento reducionista do racionalismo cartesiano (a investigação em Química era então dirigida ao nível microscópico - procurava-se esclarecer a composição das substâncias em termos de átomos e moléculas); por outro, foi feito sem estar disponível o método usado, que foi divisado pela primeira vez para a formulação do QCP, ainda que nebulosamente - segundo o próprio confessou, a formatação do QCP surgiu a Mendeliev em sonhos (mas após andar três dias a pensar intensamente no problema) [20]. O método era tão inovador que não teve qualquer observação experimental a inspirá-lo, como o banho de Arquimedes (287-267 a. C.), que o terá feito perceber o princípio da impulsão (Eureka! Tradução: Descobri!), ou a maçã de Newton (1642-1727), que o terá iluminado na formulação das leis 
da gravidade - teve de recorrer-se ao sonho para "explicar" a sua descoberta misteriosa! Em suma, a génese do QCP foi um feito notável mesmo em termos dela própria. Quanto aos seus resultados, foram também impressivos: permitiu o primeiro grande avanço sistémico de racionalização global da química (daí a designação "Sistema de Elementos" usada no título do primeiro artigo de Mendeliev sobre o QCP, 1869) [20] e, por isso, alterou completamente a percepção que se tinha deste ramo do saber - trouxe-lhe uma visão global e unificadora (até então, usando as palavras do próprio Mendeliev, "os elementos eram factos meramente fragmentários e incidentais da Natureza") [21]. ${ }^{2}$

Em suma, o gizamento do QCP mudou radicalmente a percepção que se tinha da Química - e conferiu-Ihe pela primeira vez a característica de uma ciência racional. Por todas estas razões, Mendeliev concretizou uma verdadeira Revolução Científica, no sentido que Ihe deu Kuhn [24] - um daqueles raros momentos de verdadeiro avanço da ciência em que o paradigma do saber estabelecido é substituído por outro novo, radicalmente diferente. Tais momentos constituem passos em frente gigantescos na aquisição de conhecimento pelo Homem. Por isso, Mendeliev é um bom exemplo para os químicos seguirem na adopção de uma visão holística da Química em que envolvam não só os elementos materiais como também os super-elementos, para concretizar a inflexão da trajectória actual da Civilização para uma via que conduza à Sustentabilidade - e a metáfora do QCP da Sustentabilidade pode ser muito útil para Ihes fazer ter sempre presente a premência desta tarefa gigantesca e a necessidade de envolverem sempre os três "elementos" adicionais nas suas actividades profissionais.

\section{Referências}

1. E. Montuschi, 'Metaphor in Science', em W. H. Newton-Smith (ed.), A Companion to the Philosophy of Science, Blackwell, Oxford (2001) 277-282.

2. T. L. Brown, Making Truth - Methapor in Science, University of Illinois Press, Urbana, 2003.

3. H. Beall, J. Chem. Ed. 76 (1999) 366368.

4. N. Bhusham e S. Rosenfeld, J. Chem. Ed. 72 (1995) 578-582.

5. C. W. Bowen, J. Chem. Ed. 69 (1992) 479-482.

6. K. W. Watkins, J. Chem. Ed. 66 (1989) 1020.

7. B. Hutchinson e C. Willerton, J. Chem. Ed. 65 (1988) 1048-1049.

8. J. Bermstein e S. S. Shaik, J. Chem. Ed. 65 (1988) 339-340.

9. I. Asimov, J. Chem. Ed. 36 (1959) 535538.

10. A. Johansson, 'Industrial Ecology and Industrial Metabolism: Use and Misuse of Metaphors', em R. U. Ayres e L. W. Ayres (eds), A Handbook of Industrial Ecology, E. Elgar, Cheltenham (2002) 70-75.

11. S. Erkman, J. Cleaner Prod. 5 (1997) 110.

12. T. Graedel, 'Industrial Ecology: Definition and Implementation', em R. Soclow, C. Andrews, F. Berkout e V. Thomas (eds),
Industrial Ecology and Global Change, Cambridge University Press, Cambridge (1994) 23-41.

13. R. U. Ayres, 'Industrial Metabolism', em J. H. Ausubel e H. E. Sladovich, Technology and the Environment, National Academy Press, Washington (1989) 232-49.

14. D. H. Meadows, D. L. Meadows, J. Randers e W. W. Behrens III, The Limits to Growth, Pan, Londres, 1974.

15. R. Carson, Silent Spring, Penguin, Londres, 1999 (com um Posfácio de L. Lear).

16. M .D. Gordon, A Well-ordered Thing - Dimitrii Mendeleev and the Shadow of the Periodic Table, Basic, N. Iorque, 2004.

17. J. Corish e G. M. Rosenblatt, Pure Appl. Chem. 75 (2003) 1613-1615.

18. P. J. Karol, H. Nakahara, B. W. Petley e E. Vogt, Pure Appl. Chem. 75 (2003) 16011611.

19. IUPAC, Chemistry International 27(1) (2003) 16.

20. P. Strathern, Mendeleyev's Dream - The Quest for the Elements, Hamish Hamilton, Londres, 2000, 262-294.

21. A. Findlay, A Hundred Years of Chemistry, 2. ${ }^{\text {a }}$ ed, Duckworth, Londres, 1948, 543 e 52

22. J. Gribbin, Science - A History (15432001), Penguin, Londres, 2002, 375376.

23. E. R. Malinowski, Factor Analysis in Chemistry, 2. ${ }^{a}$ ed., Wiley-Interscience, N. Iorque, 1991, ix.

24. T. S. Kuhn, The Structure of Scientific Revolutions, 3. ${ }^{\text {a }}$ ed., The University of Chicago Press, Chicago, 1996.

(2) Deve referir-se que Mendeliev, no fundo, usou precocemente uma técnica de análise estatística multivariada de dados, a análise de aglomeração, presentemente muito utilizada em Quimiometria (a estatística só foi teorizada mais tarde, na passagem do século XIX para o XX, por Pearson e sua escola). Por isso, Mendeliev deve ser considerado um dos "pais" da Quimiometria, conjuntamente com Cannizaro (1826-1910). Este também usou um raciocínio global (apresentado num panfleto em 1858, e no primeiro congresso internacional de químicos de sempre, realizado em Karlsruhe, em 1860) [20], para obter simultaneamente as massas atómicas dos elementos e os coeficientes estequiométricos nas fórmulas dos compostos a partir de uma matriz bidimensional (elementos x compostos) de volumes de combinação de elementos gasosos numa série de compostos formados a partir deles [22] - e resolver finalmente as questões de obter com segurança as massas atómicas e as fórmulas, até então objecto de muita polémica e dúvida. 0 raciocínio de Cannizaro foi um caso temporão de análise de factores, outra técnica quimiométrica actual, que só foi formalmente desenvolvida no início dos anos 30 do século XX [23]. Mendeliev e Cannizaro, portanto, devem ser considerados os precursores da Quimiometria - praticaram prematuramente técnicas de tratamento de dados que só décadas mais tarde foram teorizadas, e só ainda mais tarde, passadas mais outras tantas décadas, passaram a ser usadas pelos químicos (e nem Mendeliev nem Cannizaro tinham computador!). 